\title{
First-principles Calculation of the Electronic Structure and Optical Properties of $\mathrm{ZnO}$ Co-doped with $\mathrm{Nb}$ and $\mathrm{Ta}$
}

\author{
Jinpeng WANG ${ }^{2}$, Tao SHEN ${ }^{1,2}$, Hongchen LIU $^{3}$ \\ ${ }^{1}$ Key Laboratory of Engineering Dielectrics and Its Application, Ministry of Education, Harbin University of Science and \\ Technology, Harbin, 150080, China \\ ${ }^{2}$ College of Science, Harbin University of Science and Technology, Harbin, 150080, China \\ ${ }^{3}$ School of Electrical Engineering and Automation, Harbin Institute of Technology, Harbin, 150001, China \\ cross $^{\text {ref }}$ http://dx.doi.org/10.5755/j01.ms.25.3.19956
}

Received 16 January 2018; accepted 09 April 2018

\begin{abstract}
First-principle calculations have been performed to investigate the electronic structure and optical properties of $\mathrm{ZnO}$ codoped with $\mathrm{Nb}$ and $\mathrm{Ta}$. The three doping structures are set to: $\mathrm{Zn}_{0.9375} \mathrm{Nb}_{0.0625} \mathrm{O}, \mathrm{Zn}_{0.9375} \mathrm{Ta}_{0.0625} \mathrm{O}$ and $\mathrm{Zn}_{0.875} \mathrm{Nb}_{0.0625} \mathrm{Ta}_{0.0625} \mathrm{O}$. The experiments show that co-doping with $\mathrm{Nb}$ and Ta narrows the band gap. And it causes the Fermi level to shift upwards and enter the conduction band, while enhancing the conductivity of the doped system. In addition, it has been determined that the dielectric imaginary part of the dopant system is larger than that of the pure $\mathrm{ZnO}$ in the low energy region. The absorption side of the dopant system, on the other hand, exhibits a redshift. Furthermore, the transmittance of the ultraviolet region is significantly increased, and the function loss spectrum appears to redshift. This will provide a good theoretical basis for the study and the applications of photoelectric materials codoped with $\mathrm{Nb}$ and $\mathrm{Ta}$.

Keywords: $\mathrm{ZnO}$ co-doped with $\mathrm{Nb}$ and Ta, first-principles calculation, electronic structure, optical properties.
\end{abstract}

\section{INTRODUCTION}

In recent years, $\mathrm{ZnO}$ has attracted the attention of researchers, becoming another research hotspot, due to its superior properties as a short wavelength semiconductor material. $\mathrm{ZnO}$, a direct bandgap semiconductor material of II-VI, has an energy gap width of $3.37 \mathrm{eV}$ at room temperature and an exciton binding energy of up to 60 $\mathrm{meV}[1,2]$. In addition to its stable chemical properties and excellent photoelectric properties [3], $\mathrm{ZnO}$ also exhibits a direct band gap, large exciton binding energy, and controllable defects energy level; as a result, $\mathrm{ZnO}$ based semiconductors are recognized as a very promising photonic material in the ultraviolet (UV) and visible regions $[4,5]$. Because of these superior properties, $\mathrm{ZnO}$ has a number of applications in various fields, including transparent conductor films, solar cells, varistors, gas sensors, photo- and electro-luminescent devices, piezoelectric devices, photoconductors, thermoelectric devices, scintillation and UV sensors [6-12].

Currently, studies have focused on aspects of ZnO's applications as thin film coatings on photovoltaic devices. Studies have been performed to modify the optical properties of $\mathrm{ZnO}$ by doping different kinds of elements, at different proportions. For example, it has been demonstrated by Khan et al. that the optical absorption spectra for $\mathrm{Zr}$-doped $\mathrm{ZnO}$ nanoparticles lies within the visible region [13]. Likewise, another study [14] has determined that the electronic structure and ferromagnetic stability of $\mathrm{Cu}$-doped $\mathrm{ZnO}$ have changed significantly after doping. Furthermore, other studies have found that replacing the $\mathrm{Zn}$ atom with $\mathrm{Ag}$ or $\mathrm{Eu}$ in the $\mathrm{ZnO}$ unit cell

\footnotetext{
* Corresponding author. Tel.: +86-0451-86390727;

E-mail address: taoshenchina@163.com (T. Shen)
}

allows for the tuning of its luminescence [15-17]. In addition, the metal element co-doped $\mathrm{ZnO}$ will have a significant impact on the nature of the change. Al-Na codoped $\mathrm{ZnO}$ can improve dopant solubility, tailor the band structure of the matrix, and influence the formation of defects due to the charge compensations [18]. On the other hand, $\mathrm{Al}-\mathrm{Ga}$ co-doped $\mathrm{ZnO}$ has shown better durability against humidity, when compared to Al-doped $\mathrm{ZnO}$ [19], while $\mathrm{Ni}$ and $\mathrm{Li}$ co-doped $\mathrm{ZnO}$ has shown a significantly enhanced ferromagnetism [20]. Therefore, due to the significant effects of doping on $\mathrm{ZnO}$, the doping process of $\mathrm{ZnO}$ with various types of elements has been of major interest to researchers, both in the theoretical and experimental fields. This will, subsequently, allow for a more comprehensive understanding of the different changes in electronic structure and optical properties following the doping process of $\mathrm{ZnO}$.

As VB family elements, $\mathrm{V}, \mathrm{Nb}$ and Ta exhibit the most stable oxidation state, $\mathrm{X}+5(\mathrm{X}=\mathrm{V}, \mathrm{Nb}$ or $\mathrm{Ta})$, in natural environments. Thus, as multi-electron donors, $\mathrm{V}, \mathrm{Nb}$, and Ta are capable of improving the electrical conductivity of $\mathrm{ZnO}$-based semiconductors, thereby altering their structure and optical properties. According to previous studies [2127], good electrical conductivity and high levels of absorption in the visible light range have been observed in both $\mathrm{V}$ - and $\mathrm{Nb}$-doped $\mathrm{ZnO}$. Despite the extensive number of studies performed on ZnO-based semiconductors, researches on $\mathrm{Nb}$ - and $\mathrm{Ta}$-doped $\mathrm{ZnO}$ are still very limited. Therefore, due to the nature of $\mathrm{Nb}$ and $\mathrm{Ta}$, the fact that the electronic structure and the optical properties of $\mathrm{ZnO}$ are altered after being doped by the two elements, should not be neglected. The following study will, therefore, explore this change.

In this study, $\mathrm{ZnO}$ represents the matrix, while $\mathrm{Nb}$ and Ta are selected as the doping atoms. The first-principles 
ultrasoft pseudopotential is, then, applied to compare the changes in the band structure and optical properties of the crystals before and after $\mathrm{Nb}$ - and Ta-doping of $\mathrm{ZnO}$. Analysis of the intrinsic causes of this study is then performed, while the results obtained from the analysis can provide a theoretical reference for subsequent researches that are to be performed on $\mathrm{ZnO}$.

\section{MODEL AND COMPUTIONAL METHODS}

Density function theory (DFT) calculation was performed within the generalized gradient approximation (GGA), with the correction of Perdew-Burke-Ernzerhof (PBE) to account for the exchange-correction potential as employed in the software of Cambridge Sequential Total Energy Package (CASTEP) Code of Materials Studio, and used the method of plane-wave pseudopotentials [28, 29]. In addition, the Materials Visualizer was employed to build the $\mathrm{ZnO}$ model.

The ideal structure of $\mathrm{ZnO}$ exhibits a hexagonal wurtzite crystal structure with the corresponding space group symmetry of $\mathrm{P} 63 \mathrm{mc}$, with the primitive cell parameters listed as follows: $a=b=0.3249 \mathrm{~nm}$, $\mathrm{c}=0.5204 \mathrm{~nm}, \alpha=\beta=90^{\circ}$, and $\gamma=120^{\circ}$ [30]. Based on the primitive cell, a $2 \times 2 \times 2 \mathrm{ZnO}$ supercell was constructed as the model of the $\mathrm{ZnO}$. Fig. $1 \mathrm{a}$ and $\mathrm{b}$ shows a Nb-doped $\mathrm{ZnO}$ ( $\mathrm{ZnO}: \mathrm{Al})$, which corresponds to $\mathrm{Zn}_{0.9375} \mathrm{Nb}_{0.0625} \mathrm{O}$, with one $\mathrm{Nb}$ atom substituting one of the $\mathrm{Zn}$ atoms. Figure 1(c), on the other hand, shows a Tadoped $\mathrm{ZnO}$ (ZnO:Ta) which corresponds to $\mathrm{Zn}_{0.9375} \mathrm{Nb}_{0.0625} \mathrm{O}$, where one $\mathrm{Nb}$ atom substitutes one $\mathrm{Zn}$ atom. Likewise, Fig. $1 \mathrm{~d}$ represents the model of $\mathrm{ZnO}$ codoped with $\mathrm{Nb}$ and $\mathrm{Ta}$ ( $\mathrm{ZnO}: \mathrm{Nb}-\mathrm{Ta}$ ) which corresponds to $\mathrm{Zn}_{0.875} \mathrm{Nb}_{0.0625} \mathrm{Ta}_{0.0625} \mathrm{O}$, in which one $\mathrm{Nb}$ atom substitutes one $\mathrm{Zn}$ atom, and one Ta atom substitutes another one of the $\mathrm{Zn}$ atoms.

In addition, ultrasoft pseudopotentials are used to replace the nuclei. The electronic valance configurations for each of the atomic species were denoted as: $\mathrm{Zn}$ $3 \mathrm{~d} 104 \mathrm{~s} 2$, O-2s22p4, Nb-4d45s1, and Ta-5d36s2. After

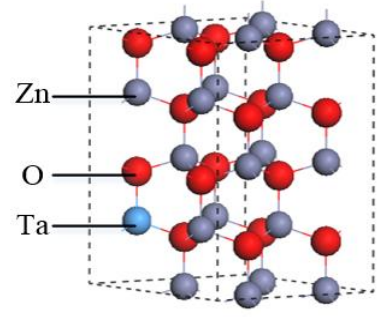

a

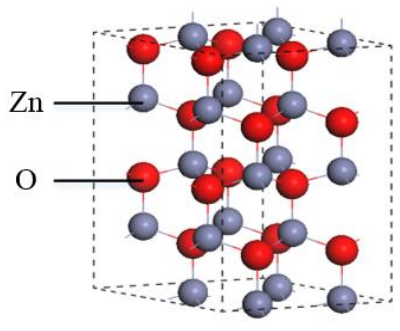

c performing a careful convergence test and contrast, the cutoff energy of the plane wave was assumed as $460 \mathrm{eV}$. Brillouin zone wavevector $k$ points were then performed over a $4 \times 4 \times 2$ grid size which was generated automatically by the Monkhorst-Pack method [31]. Furthermore, during the optimization process, a total energy convergence of $0.5 \times 10^{-6} \mathrm{eV} /$ atom, HellmannFeynman ionic force of $0.001 \mathrm{eV} / \mathrm{nm}$, maximum stress of $0.02 \mathrm{~Pa}$, and maximum displacement of $0.5 \times 10^{-5} \mathrm{~nm}$ have been applied. Additionally, the scissors operation has been carried out in the optical absorption of $\mathrm{ZnO}$ in order to obtain the exact values of the optical absorption spectra within low energy ranges.

\section{RESULTS AND DISCUSSION}

\subsection{Results of optimized structure}

In order to determine the feasibility of the experimental data, we optimized the equilibrium structure using experimental methods and related parameters which were mentioned in Model and computational methods. Table 1 shows the experimental and calculated lattice constants, and the volume $\mathrm{V}$ of $\mathrm{ZnO}$. Additionally, the lattice parameters of optimized $\mathrm{ZnO}$ doped systems have also been compared with $\mathrm{ZnO}$ lattice parameters in several papers which used the same experimental principle. Exp.a, Exp.b, Exp.c, respectively, is the data in different references. Cal.d is the lattice parameter before optimization, and Cal.e is lattice parameter obtained after calculation and optimization. The lattice constant which we calculated $a$ and $c$, and the volume $V$ of pure $\mathrm{ZnO}$, and $\mathrm{Nb}-$, Ta-, and $\mathrm{ZnO}$ co-doped with $\mathrm{Nb}$ and $\mathrm{Ta}$, are shown in Table 2. As shown in Table 1, the parametric values, after optimization, of $a$ and $c$ were calculated as 3.272 and 5.261 respectively, which are in good agreement with the experimental values [2, 30, 32, 33]. Meanwhile, it can be perceived that the lattice constants of doped $\mathrm{ZnO}$ increased gradually, as shown in Table 2.

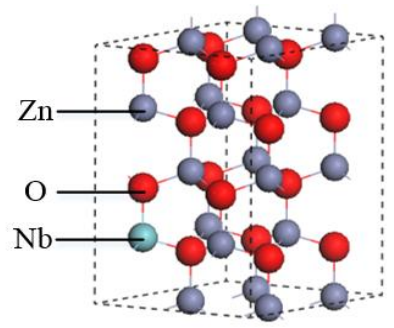

b

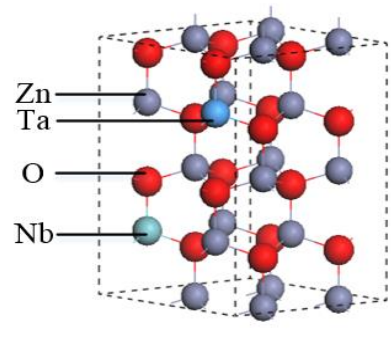

d

Fig. 1. Schematic of the structures of $\mathrm{ZnO}(2 \times 2 \times 2)$ supercells: $\mathrm{a}-\mathrm{ZnO} ; \mathrm{b}-\mathrm{Zn} 0.9375 \mathrm{Nb}_{0.0625} \mathrm{O} ; \mathrm{c}-\mathrm{Zn} 0.9375 \mathrm{Ta} 0.0625 \mathrm{O}$; $\mathrm{d}-\mathrm{Zn} 0.875 \mathrm{Nb}_{0.0625} \mathrm{Ta} 0.0625 \mathrm{O}$ 
Table 1. Experimental and calculated lattice constants, $(a=b, c)$, and volume $V$ of $\mathrm{ZnO}$

\begin{tabular}{|l|c|c|c|c|}
\hline & $a, \mathrm{~nm}$ & $c, \mathrm{~nm}$ & $V, \mathrm{~nm}^{3}$ & $c / a$ \\
\hline Exp.a [2] & 0.3283 & 0.5311 & $49.573 \times 10^{-3}$ & 1.618 \\
\hline Exp.b [32] & 0.3247 & 0.5203 & $47.506 \times 10^{-3}$ & 1.602 \\
\hline Exp.c [33] & 0.3278 & 0.5295 & $49.274 \times 10^{-3}$ & 1.615 \\
\hline Cal.d [30] & 0.3249 & 0.5204 & $47.574 \times 10^{-3}$ & 1.602 \\
\hline Cal. e (Present Study) & 0.3272 & 0.5261 & $48.778 \times 10^{-3}$ & 1.608 \\
\hline
\end{tabular}

Table 2. Lattice constants $a$ and $c$ and volume $V$ of pure $\mathrm{ZnO}$, $\mathrm{Nb}$-, Ta-, $\mathrm{ZnO}$ co-doped with $\mathrm{Nb}$ and $\mathrm{Ta}$

\begin{tabular}{|c|c|c|c|c|}
\hline & $a, \mathrm{~nm}$ & $c, \mathrm{~nm}$ & $V, \mathrm{~nm}$ & $c / a$ \\
\hline Pure $\mathrm{ZnO}$ & 3.272 & 5.261 & $48.778 \times 10^{-3}$ & 1.608 \\
\hline $\mathrm{Zn}_{0.9375} \mathrm{Nb}_{0.0625} \mathrm{O}$ & 3.379 & 5.492 & $54.305 \times 10^{-3}$ & 1.625 \\
\hline $\mathrm{Zn}_{0.9375} \mathrm{Ta}_{0.0625} \mathrm{O}$ & 3.381 & 5.571 & $55.151 \times 10^{-3}$ & 1.648 \\
\hline $\begin{array}{c}\mathrm{Zn}_{0.875} \mathrm{Nb}_{0.0625} \mathrm{Ta} \\
0.0625 \mathrm{O}\end{array}$ & 3.458 & 5.779 & $59.846 \times 10^{-3}$ & 1.671 \\
\hline
\end{tabular}

According to the results, the $\mathrm{Nb}$-doped $\mathrm{ZnO}$ and $\mathrm{Ta}-$ doped $\mathrm{ZnO}$ show the least lattice distortion and doping feasibility. On the contrary, $\mathrm{ZnO}$ co-doped with $\mathrm{Nb}$ and $\mathrm{Ta}$ exhibits serious lattice distortion and unacceptable mismatch with $+0.0186 \mathrm{~nm}$ and $+0.0518 \mathrm{~nm}$ for $a$ and $\mathrm{c}$ respectively; these discrepancies may be attributed to the large ionic radius of $\mathrm{Nb}^{5+}$ and $\mathrm{Ta}^{5+}$. Even so, it was determined that the changes of $\mathrm{ZnO}$ co-doped with $\mathrm{Nb}$ and Ta observed in the values of $\mathrm{a}$ and $\mathrm{c}$ are still in an allowable range. Thus, we can clearly observe that the $\mathrm{Nb}$ doped $\mathrm{ZnO}$, Ta-doped $\mathrm{ZnO}$, and $\mathrm{ZnO}$ co-doped with $\mathrm{Nb}$ and Ta exhibit feasibility. The results obtained are, therefore, consistent with literature on $\mathrm{Nb}$-doped $\mathrm{ZnO}$, as reported by Shaw et al. [34], and on Ta-doped $\mathrm{ZnO}$, as reported by $\mathrm{Wu}$ et al. [35].

\subsection{Band structure}

The band structures of pure $\mathrm{ZnO}$ and $\mathrm{ZnO}$ doped systems are shown in Fig. 2. Because the nature of the

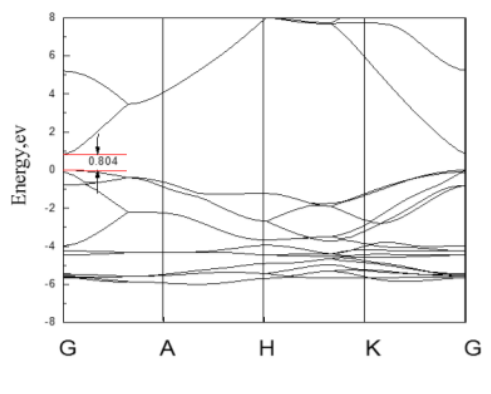

a

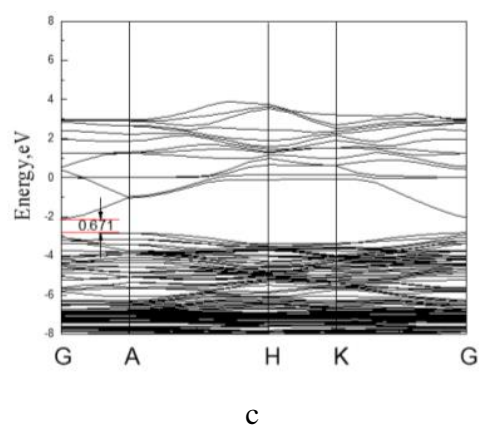

material is mainly determined by the change in the vicinity of the Fermi level, caused by the doping of $\mathrm{ZnO}$, the Fermi level at zero energy, and at -8 to $8 \mathrm{eV}$ of the band structure are shown in Fig. 2. Fig. 2 a shows the band structure of pure $\mathrm{ZnO}$. As observed, the $\mathrm{ZnO}$ semiconductor exhibits a direct band gap due to its valence band at the top and bottom of the conduction bands, which are located at point $G$ in Fig. 2 a. Additionally, the band gap width is determined as $0.804 \mathrm{eV}$. The result obtained is in close agreement with those calculated by Si X et al. [36] at $0.731 \mathrm{eV}$. However, this is still far from the band gap with a value of $3.37 \mathrm{eV}$, for pure $\mathrm{ZnO}$, and this difference can be attributed to the generally low phenomenon in the calculation of band gaps present in DFT. For pure $\mathrm{ZnOs,} \mathrm{the} \mathrm{energy} \mathrm{of} \mathrm{Zn} 3 \mathrm{~d}$ is overestimated, which leads to its enhanced interaction with $\mathrm{O} 2 \mathrm{p}$, and as a result, the band gap's bandwidth becomes larger, hence the lowering of the band gap. Despite the underestimation of the band-gap, the optical spectrum is predicted well by the DFT calculation [37]. A common way of fixing the underestimated band gap is to apply a rigid energy shift to the computed Kohn-Sham spectra, which is called a scissor operation.

It can be seen from Fig. 2 that the maximum values of the valence band and the minimum values of the conduction band in the three cases of the $\mathrm{ZnO}$ doping still remain at point $\mathrm{G}$. This means that the doped $\mathrm{ZnO}$ still belongs to the category of direct band gap oxides. Moreover, it has also been determined that $\mathrm{Nb}$-doped $\mathrm{ZnO}$, Ta-doped $\mathrm{ZnO}$, and $\mathrm{ZnO}$ co-doped with $\mathrm{Nb}$ and $\mathrm{Ta}$ band gaps are narrow, and the degree of narrowing of the codoped conditions is the greatest at $0.664 \mathrm{eV}, 0.671 \mathrm{eV}$ and $0.614 \mathrm{eV}$ respectively. Thus, the conductivity of $\mathrm{ZnO}$, after doping, was enhanced. In addition, we can also determine that the conduction and valence bands of the doped systems move downwards, correspondingly.
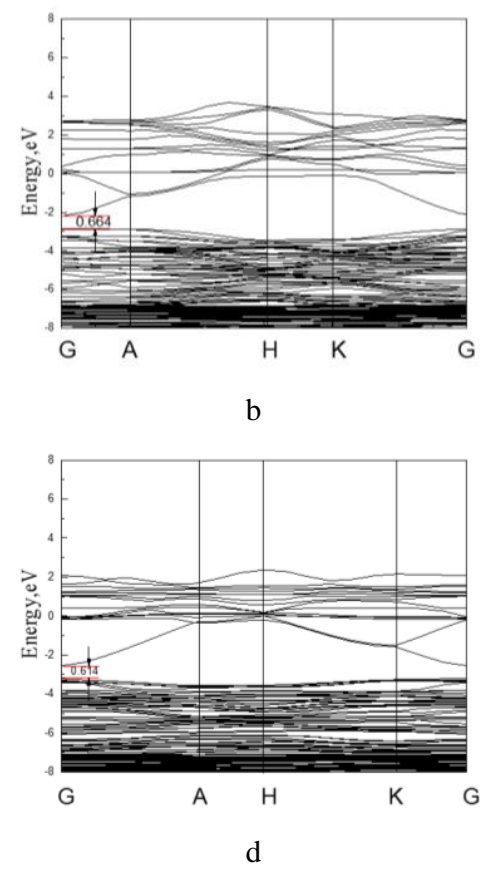

Fig. 2. Band structures of pure $\mathrm{ZnO}$ and $\mathrm{ZnO}$ doped systems: $\mathrm{a}-\mathrm{ZnO} ; \mathrm{b}-\mathrm{Nb}-\mathrm{ZnO} ; \mathrm{c}-\mathrm{Ta}-\mathrm{ZnO} ; \mathrm{d}-(\mathrm{Nb}, \mathrm{Ta})-\mathrm{ZnO}$ 


\subsection{Density of states}

Fig. 3 shows the total density of states (TDOS) and partial density of states (PDOS) of the pure $\mathrm{ZnO}$ and $\mathrm{ZnO}$ doping systems. As observed in Fig. 2 a, the valence band of pure $\mathrm{ZnO}$ can be divided into three parts. Within the range of -4.41 to $0 \mathrm{eV}$, it is mainly composed of $\mathrm{O} 2 \mathrm{p}$ and small amounts of $\mathrm{Zn} 3 \mathrm{~d}$ states. On the other hand, valence bands within the range of -6.63 to $4.41 \mathrm{eV}$ are mainly composed of $\mathrm{Zn} 3 \mathrm{~d}$ and partial $\mathrm{O} 2 \mathrm{p}$ states. Lastly, an isolated band in the range of -18.3 to $16.5 \mathrm{eV}$ at the valence band is formed with $\mathrm{O} 2 \mathrm{~s}$ state. The composition of conduction bands, on the other hand, is consistent with the total density of $\mathrm{ZnO}$ in that they are mainly formed by the $\mathrm{Zn} 4 \mathrm{~s}$ and the $\mathrm{O} 2 \mathrm{p}$ states.

The TDOS and PDOS of the $\mathrm{ZnO}$ doping systems are shown in Fig. $3 b-d$ ). As observed, the Fermi level is shifted upwards, and into the conduction band after doping, as the doping of $\mathrm{Nb}$ and $\mathrm{Ta}$ elements leads to an increase in conductive carriers. This also leads to enhanced conductivity of the systems after doping, especially after co-doping. In Fig. 3 b, we can see that there exists an impurity level near the Fermi level, after doping $\mathrm{Nb}$, which is caused by the $\mathrm{Nb} 4 \mathrm{~d}$ state, and as a result, causes the conduction band width to become smaller. In addition, there are two isolated bands in the range of -58.0 to $56.7 \mathrm{eV}$ and -34.3 to $-32.6 \mathrm{eV}$ at the valence band, which is formed by the $\mathrm{Nb} 5 \mathrm{~s}$ and $4 \mathrm{p}$ states. Nonetheless, these are far from the Fermi level, and, therefore, the impact is small and does not require significant consideration.

As shown in Fig. 3 c, the effects on the Fermi level is attributed to the Ta $5 \mathrm{~d}$ state after doping, and is mainly composed of the Ta $5 \mathrm{~d}$ and the partial O $2 \mathrm{p}$ states at the valence band between -1.32 and $3.76 \mathrm{eV}$. Since the $4 \mathrm{~s}$
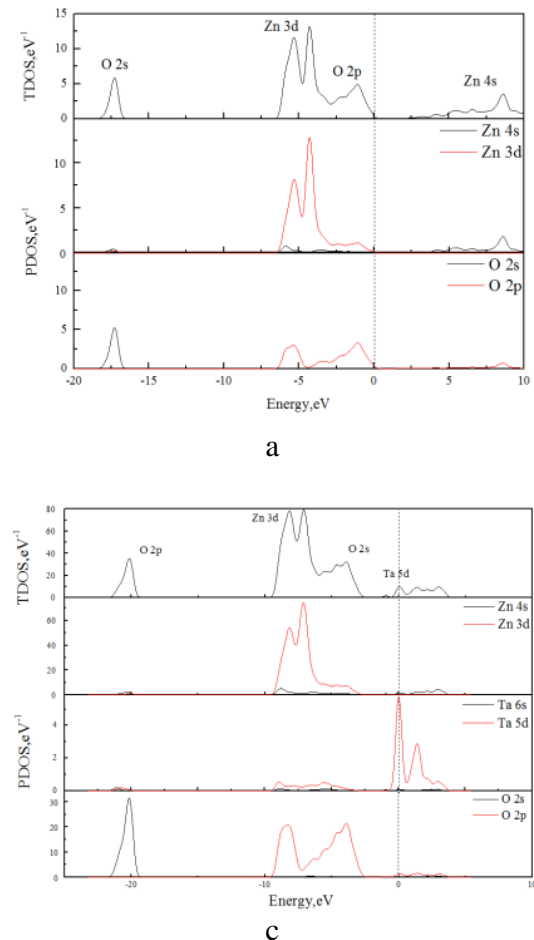

electrons of $\mathrm{Zn}$ and $5 \mathrm{~d}$ electrons of Ta are decreasing and increasing, respectively, the contribution of $\mathrm{Zn}$ in the conduction band is gradually weakened.

Fig. $3 \mathrm{~d}$ shows the TDOS and PDOS of $\mathrm{ZnO}$ co-doped with $\mathrm{Nb}$ and $\mathrm{Ta}$. After co-doping, the s orbital electron density of $\mathrm{Nb}$ and $\mathrm{Ta}$ has very little influence on the valence and conduction bands of the $\mathrm{ZnO}$ crystal, and only functions at a deeper level $(<-30 \mathrm{eV})$. The maximum effect on the bottom of the conduction band and the top of the valence band are still attributed to the $\mathrm{Nb} 4 \mathrm{~d}$ and $\mathrm{Ta} 5 \mathrm{~d}$ states.

According to the analyses made above, in $\mathrm{ZnO}$ codoped with $\mathrm{Nb}$ and $\mathrm{Ta}$, the interactions between the impurity atoms will narrow down the forbidden band width, while shifting the Fermi level upwards. At the same time, the quantum state close to the bottom of the conduction band has been occupied by electrons, whereby the degeneration of carriers takes place to form degenerate semiconductors. This, therefore, obtains n-type semiconductors which exhibit better electrical properties.

\subsection{Optical properties}

\subsubsection{Dielectric function}

The dielectric function can reflect the information between the energy band structure and the optical spectrum of the solid, and can characterize the physical properties of the material. The macroscopic optical response function is usually described by the complex permittivity $\varepsilon(\omega)$ of light, where $\varepsilon(\omega)=\varepsilon_{1}(\omega)+\varepsilon_{2}(\omega)$. Where, $\omega$ denotes the frequency, and $\varepsilon_{1}(\omega)$ and $\varepsilon_{2}(\omega)$ represent the real and imaginary parts of the dielectric function, respectively.

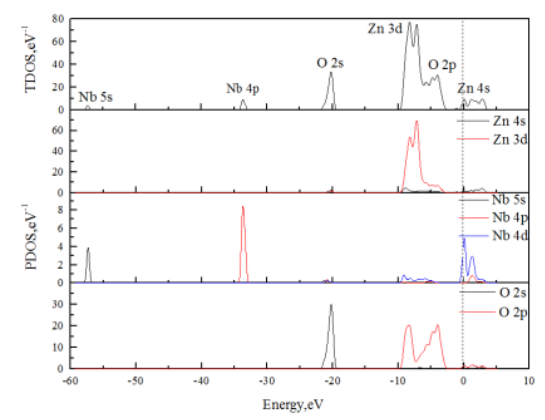

$\mathrm{b}$

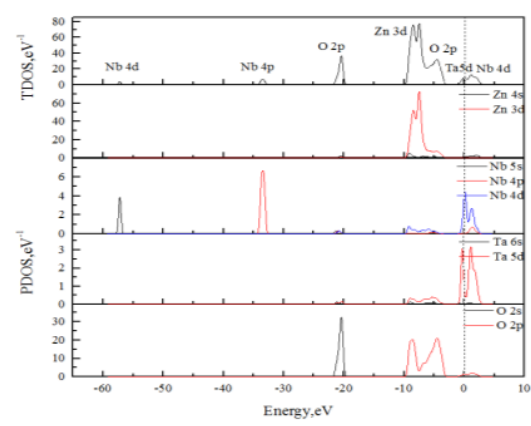

d

Fig. 3. TDOS and PDOS of pure $\mathrm{ZnO}$ and $\mathrm{ZnO}$ doping systems, where the Fermi level is set to $0: \mathrm{a}-\mathrm{ZnO}, \mathrm{b}-\mathrm{Nb}-\mathrm{ZnO} ; \mathrm{c}-\mathrm{Ta}-\mathrm{ZnO}$; $\mathrm{d}-(\mathrm{Nb}, \mathrm{Ta})-\mathrm{ZnO}$ 
According to the definition of Kramers-Kronig dispersion relation and direct transition probability, we can deduce the real part $\varepsilon_{1}$ and the imaginary part $\varepsilon_{2}$ of the crystal dielectric function. The results are as follows:

$$
\begin{aligned}
\varepsilon_{1}(\omega) & \left.=1+\mathrm{c}_{2} \sum_{c, v B Z} \int_{B Z} \mathrm{~d}^{3} k \frac{2}{2 \pi} f\left|\mathrm{E}_{c}(k)-\mathrm{M}_{c v}(k)\right|^{2}(k)\right] \\
& \times \frac{\hbar^{3}}{\left[\mathrm{E}_{c}(k)-\mathrm{E}_{v}(k)\right]^{2}-\hbar^{2} \omega^{2}} \\
\varepsilon_{2}(\omega) & =\frac{4 \pi^{2}}{\mathrm{~m}^{2} \omega^{2}} \sum_{c, v} \int_{B, Z} \mathrm{~d}^{2} k \frac{2}{2 \pi}\left|\mathrm{e} \cdot \mathrm{M}_{c v}(k)\right|^{2} . \\
& \times \delta\left[\mathrm{E}_{c}(k)-\mathrm{E}_{v}(k)-\hbar \omega\right]
\end{aligned}
$$

In the equation, $\hbar=\mathrm{h} / 2, \mathrm{~m}, \mathrm{e}$, and $\omega$ represent the free electron mass, free electron charge, and incident photon frequency, respectively. And where, $c, v, B Z, k$, and $\left|\mathrm{e} \cdot \mathrm{M}_{c v}(k)\right|^{2}$ denote the conduction band, valence band, first Brillouin zone, reciprocal lattice vector, and the momentum transition matrix element, respectively, while $\mathrm{E}_{\mathrm{c}}(\mathrm{k})$ represents the conduction band on the intrinsic level, and $E_{\mathrm{v}}(\mathrm{k})$ is the valence band on the intrinsic level.

Since the imaginary part $\varepsilon_{2}$ of the crystal dielectric function describes the energy required for the transition of the electron from the valence band to the conduction band, we only analyze the imaginary part of the dielectric function. Fig. 4 shows the pure $\mathrm{ZnO}$ and the doped $\mathrm{ZnO}$ dielectric functions of the imaginary part. As shown in Fig. 4, when compared to pure $\mathrm{ZnO}$, the imaginary part of the dielectric function becomes smooth after doping the impurity atoms. There is only one larger dielectric peak, between 2.68 and $2.85 \mathrm{eV}$. This corresponds to the direct transitions between $\mathrm{O} 2 \mathrm{p}, \mathrm{Nb} 4 \mathrm{~d}$, and Ta $5 \mathrm{~d}$ states in the state density map. A rise in the dielectric peaks are observed in all $\mathrm{Nb}$-doped $\mathrm{ZnO}$, Ta-doped $\mathrm{ZnO}$, and $\mathrm{ZnO}$ co-doped with $\mathrm{Nb}$ and $\mathrm{Ta}$ systems.

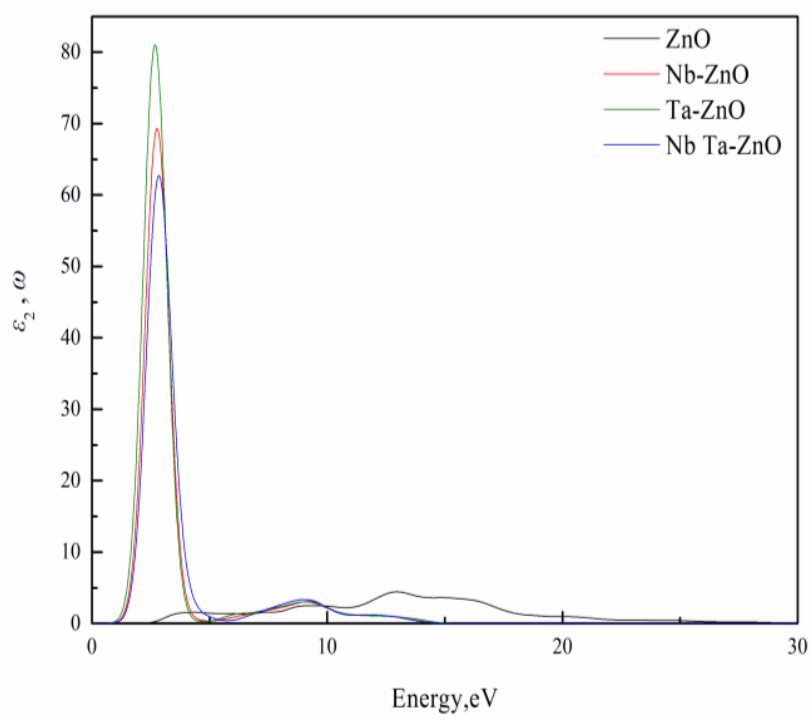

Fig. 4. Intrinsic $\mathrm{ZnO}$ and the doping $\mathrm{ZnO}$ dielectric function of the imaginary part $\varepsilon_{2}$
In $\mathrm{Nb}$ and $\mathrm{Ta}$ co-doped $\mathrm{ZnO}$, the dielectric peak moves slightly towards the high energy direction. This is due to the fact that the Fermi level enters the conduction band after the impurity is doped on the $\mathrm{ZnO}$, therefore, the conduction band is filled with electrons at the Fermi level. This results in the transition of the electronic valence band to the Fermi level and above, hence increasing the required energy. Furthermore, in the case of $\mathrm{ZnO}$ codoped with $\mathrm{Nb}$ and $\mathrm{Ta}$, the interaction between the $\mathrm{Nb}$ atom and the Ta atom causes the energy required for the electron transition to be less than the energy required for a single doping, hence the lower value of the peak of codoping relative to that of the single doping peak, with a range between 2.68 and $2.85 \mathrm{eV}$.

\subsubsection{Absorption}

The absorption spectrum can reflect the absorption versus wavelength loops of the doped $\mathrm{ZnO}$ to different wavelengths of light [38, 39]. The absorption coefficient can be directly derived from $\varepsilon_{1}(\omega)$ and $\varepsilon_{2}(\omega)$. The form of expression [40] is as follows:

$\mathrm{I}(\omega)=\sqrt{2} \omega\left[\sqrt{\varepsilon_{1}^{2}(\omega)-\varepsilon_{2}^{2}(\omega)}-\varepsilon_{1}(\omega)\right]^{1 / 2}$.

The absorption coefficient of pure $\mathrm{ZnO}$ and doped $\mathrm{ZnO}$ is shown in Fig.5. There are three distinct absorption peaks in pure $\mathrm{ZnO}$, located at $10.07 \mathrm{eV}, 16.87 \mathrm{eV}$, and $20.69 \mathrm{eV}$. After the incorporation of impurities, the absorption peak decreases, especially in $\mathrm{Nb}$ and $\mathrm{Ta}$ codoped $\mathrm{ZnO}$. The absorption peak is mainly derived from the transition of the valence band to the electron band in the excited state, while the weakening of the absorption peak indicates that the reduction of the transition process is due to the incorporation of $\mathrm{Nb}$ and Ta impurity atoms. In addition, since the new impurity band is introduced after doping, a new absorption peak appears in the low energy region. Moreover, it is clearly perceived that the absorption side exhibits a redshift phenomenon as the doping of $\mathrm{Nb}$ and $\mathrm{Ta}$ atoms leads to a reduction in the forbidden band width.

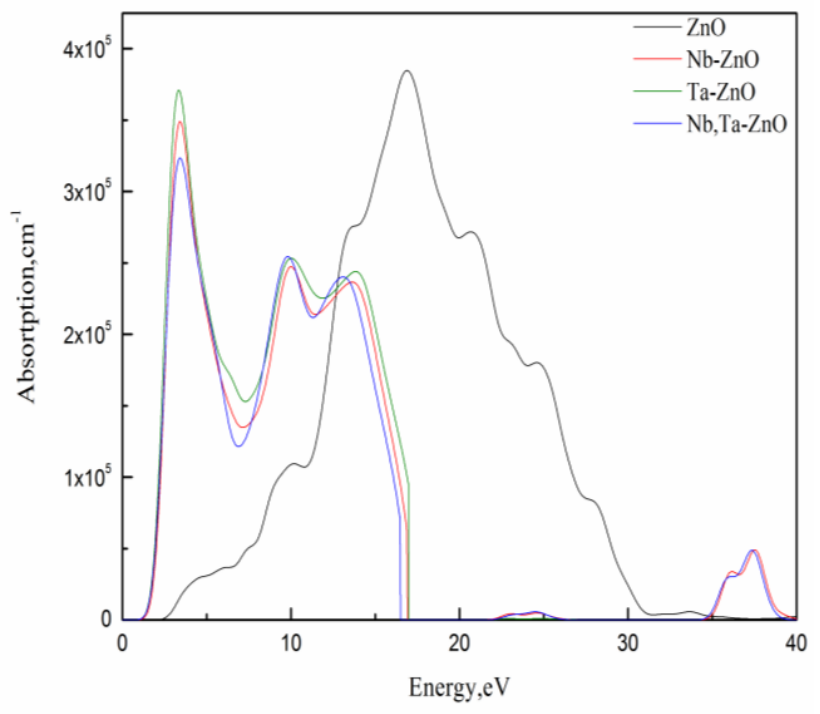

Fig. 5. The absorption coefficients of pure $\mathrm{ZnO}$ and doped $\mathrm{ZnO}$ 


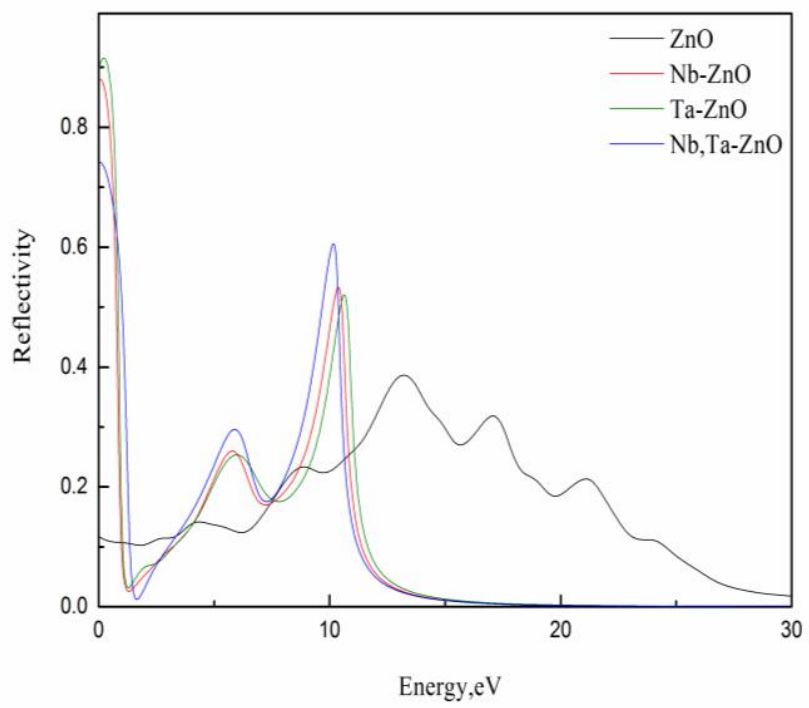

Fig. 6. The reflectivity of pure $\mathrm{ZnO}$ and doped $\mathrm{ZnO}$

This is mainly due to the energy structures of $\mathrm{Nb}$ and Ta elements, which significantly improves the absorption property of $\mathrm{ZnO}$ after doping.

\subsubsection{Reflectivity}

The change in reflectivity is observed before and after $\mathrm{ZnO}$ doping, as shown in Fig. 6. The main peak of the reflection of pure $\mathrm{ZnO}$ is located close to a value of $13.24 \mathrm{eV}$. After doping, the main peak moves towards the low energy region. $\mathrm{Nb}$ and $\mathrm{Ta}$ co-doped $\mathrm{ZnO}$ has the largest variation in this case. Although the trend is decreasing in the high energy region, the reflectivity of the high energy region after doping of $\mathrm{Nb}$ and $\mathrm{Ta}$ is lower than that of pure $\mathrm{ZnO}$. And the doped $\mathrm{ZnO}$ decreased its absorption and reflectivity in the $20-30 \mathrm{eV}$ high-energy region. This implies that the transmittance of the ultraviolet region in the $20-30 \mathrm{eV}$ high-energy region after doping of $\mathrm{Nb}$ and $\mathrm{Ta}$ elements is significantly increased, especially when $\mathrm{Nb}$ and $\mathrm{Ta}$ is co-doped with $\mathrm{ZnO}$. In addition, $\mathrm{Nb}$ and $\mathrm{Ta}$ co-doped $\mathrm{ZnO}$ systems has the lowest reflectivity in the visible range. However, the reflectivity of $\mathrm{ZnO}$-doped systems in the low-energy UV region increases again to the highest level.

\subsubsection{Loss function}

The energy loss spectrum is a physical quantity that describes the loss of energy of electrons through uniform dielectrics. The loss function $\mathrm{L}(\omega)$, is described in terms of $\varepsilon_{1}(\omega)$ and $\varepsilon_{2}(\omega)$ as:

$$
\mathrm{L}(\omega)=\varepsilon_{2}(\omega)\left[\varepsilon_{1}^{2}(\omega)+\varepsilon_{2}^{2}(\omega)\right]
$$

As shown in Fig. 7, the energy-loss peak of pure $\mathrm{ZnO}$ is close to a value of $14.35 \mathrm{eV}$. In this case of doping, the energy loss peak appears redshift, where the energy-loss peak of $\mathrm{Nb}$ and $\mathrm{Ta}$ co-doped $\mathrm{ZnO}$ has the largest redshift. It is clearly seen that two energy loss peaks are present after doping; this corresponds to the two sharp descending segments of the reflection spectrum in Fig. 6.

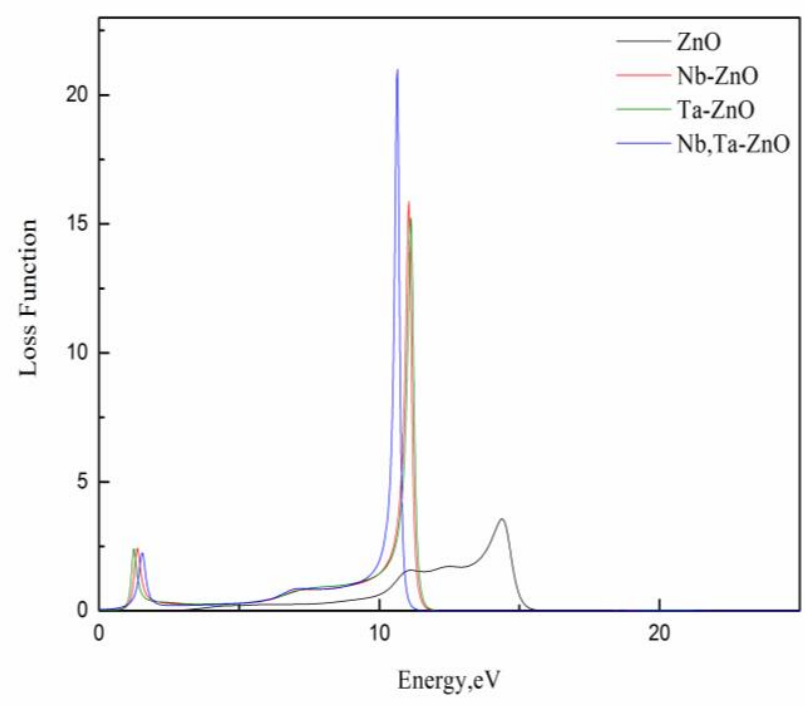

Fig. 7. The loss function of pure $\mathrm{ZnO}$ and doped $\mathrm{ZnO}$

\section{CONCLUSIONS}

The electronic structure and optical properties of $\mathrm{ZnO}$ co-doped with $\mathrm{Nb}$ and $\mathrm{Ta}$ have been investigated using the first-principles ultrasoft pseudopotential within GGA. A summary of our results are as follows:

1. In this study, the direct band gap of the $\mathrm{ZnO}$ was determined as $0.804 \mathrm{eV}$. After doping, the forbidden band width becomes smaller, and the co-doped band gap is the smallest.

2. After doping, impurity atoms provide free carriers near the Fermi level, while the Fermi level shifts upwards into the conduction band. This significantly improves the conductivity of the dopant system.

3. In terms of optical properties, the dielectric imaginary part of the dopant system is larger than the pure $\mathrm{ZnO}$ in the low energy region.

4. The absorption side of the dopant system exhibits a redshift phenomenon. Meanwhile, the doping system still has different degrees of absorption when the energy is higher than $34.69 \mathrm{eV}$.

5. After doping of $\mathrm{Nb}$ and $\mathrm{Ta}$ elements, the transmittance of the ultraviolet region is significantly increased in the $20-30 \mathrm{eV}$ high-energy region, especially when $\mathrm{Nb}$ and $\mathrm{Ta}$ is co-doped with $\mathrm{ZnO}$. $\mathrm{Nb}$ and $\mathrm{Ta}$ co-doped $\mathrm{ZnO}$ systems has the lowest reflectivity in the visible range. And the reflectivity of $\mathrm{ZnO}$-doped systems in the low-energy UV region increases again to the highest level.

6. The function loss spectrum appears redshift and the energy-loss peak of $\mathrm{Nb}$ and $\mathrm{Ta}$ co-doped $\mathrm{ZnO}$ has the largest redshift.

\section{Acknowledgments}

This work was supported by the National Natural Science Foundation of China [grant number 51677044] and the Outstanding Youth Innovation Foundation of Harbin [grant number 2017RAYXJ022]. 


\section{REFERENCES}

1. Li, Y., Zhao, X., Fan, W. Structural, Electronic, and Optical Properties of Ag-Doped $\mathrm{ZnO}$ Nanowires: First Principles Study Journal of Physical Chemistry C 115 (9) 2011: pp. 3552-3557. https://doi.org/10.1021/jp1098816

2. Li, L., Wang, W., Liu, H., Liu, X., Song, Q., Ren, S. First Principles Calculations of Electronic Band Structure and Optical Properties of Cr-Doped $\mathrm{ZnO}$ The Journal of Physical Chemistry C 113 (19) 2009: pp. 8460-8464. https://doi.org/10.1021/jp811507r

3. Zhou, Z., Komori, T., Ayukawa, T., Yukawa, H., Morinaga, M., Koizumi, A., Takeda, Y. Li-and Ercodoped $\mathrm{ZnO}$ with Enhanced $1.54 \mu \mathrm{m}$ Photoemission Applied Physics Letters 87 (9) 2005: pp. 091109.

https://doi.org/10.1063/1.2035867

4. Reynolds, D.C., Look, D.C., Jogai, B., Collins, T.C. Polariton and Free-exciton-like Photoluminescence in $\mathrm{ZnO}$ Applied Physics Letters 79 (2; 43) 2001: pp. 3794 https://doi.org/10.1063/1.1412435

5. Gopal, P., Spaldin, N.A. Magnetic Interactions in Transition-metal-doped ZnO: An Ab Initio Study Physical Review B 74 (9) 2006: pp. 094418. https://doi.org/10.1103/PhysRevB.74.094418

6. Erhart, P., Albe, K. First-principles Study of Migration Mechanisms and Diffusion of Oxygen in Zinc Oxid Physical Review B 73 (11) 2006: pp. 115207. https://doi.org/10.1103/PhysRevB.73.115207

7. Chuang, C.-H.-M., Brown, P.-R., Bulović, V., Bawendi, M.-G. Improved Performance and Stability in Quantum dot Solar Cells through Band Alignment Engineering Nature Materials 13 (8) 2014: pp. 796-801. https://doi.org/10.1038/nmat3984

8. Iwata, K., $\quad$ Tampo, H., $\quad$ Yamada, A., $\quad$ Fons, P., Matsubara, K., Sakurai, K., Ishizuka, S., Niki, S. Growth of $\mathrm{ZnO}$ and Device Applications Applied Surface Science 244 (1) 2005: pp. 504-510.

https://doi.org/10.1016/j.apsusc.2004.10.109

9. Esro, M., Vourlias, G., Somerton, C., Milne, W.I., Adamopoulos, G. High-mobility $\mathrm{ZnO}$ Thin Film Transistors Based on Solution-processed Hafnium Oxide Gate Dielectrics Advanced Functional Materials 25 (1) 2015: pp. $134-141$.

https://doi.org/10.1002/adfm.201402684

10. Amrani, A.El., Hijazi, F., $\quad$ Lucas, B., $\quad$ Boucle, J., Aldissi, M. Electronic Transport and Optical Properties of Thin Oxide Films Thin Solid Films 518 (16) 2010: pp. $4582-4585$. https://doi.org/10.1016/j.tsf.2009.12.036

11. Rackauskas, S., Klimova, O., Jiang, H., Nikitenko, A., Chernenko, K.A., Shandakov, S.D., Kauppinen, E.I., Tolochko, O.V., Nasibulin, A.G. A Novel Method for Continuous Synthesis of $\mathrm{ZnO}$ Tetrapods The Journal of Physical Chemistry C 119 (28) 2015: pp. 16366-16373. https://doi.org/10.1021/acs.jpcc.5b03702

12. Rackauskas, S., Mustonen, K., Järvinen, T., Mattila, M., Klimova, O., Jiang, H., Tolochko, O., Lipsanen, H., Kauppinen, E.I., Nasibulin, A.G. Synthesis of $\mathrm{ZnO}$ Tetrapods for Flexible and Transparent UV Sensors Nanotechnology 23 (9) 2012: pp. 095502. https://doi.org/10.1088/0957-4484/23/9/095502

13. Khan, I., Khan, S., Nongjai, R., Ahmed, H., Khan, W. Structural and Optical Properties of Gel-combustion
Synthesized $\mathrm{Zr}$ Doped $\mathrm{ZnO}$ Nanoparticles Materials 35 (6) 2013: pp. 1189-1193. https://doi.org/10.1016/j.optmat.2013.01.019

14. Huang, L.M., Rosa, A.L., Ahuja, R. Ferromagnetism in $\mathrm{Cu}$-doped $\mathrm{ZnO}$ from First-principles Theory Physical Review B 74 (7) 2006: pp. 075206. https://doi.org/10.1103/PhysRevB.74.075206

15. Duan, L., Lin, B., Zhang, W., Zhong, S., Fu, Z. Enhancement of Ultraviolet Emissions from ZnO Films by Ag Doping Applied Physics Letters 88 (23)

2006: pp. 232110. https://doi.org/10.1063/1.2211053

16. Wang, X.B., Song, C., Geng, K.W., Zeng, F., Pan, F. Luminescence and Raman Scattering Properties of AgDoped ZnO Films Journal of Physics D: Applied Physics 39 (23) 2006: pp. 4992. https://doi.org/10.1088/0022-3727/39/23/014

17. Pan, H., Yi, J.B., Shen, L., Wu, R.Q., Yang, J.H., Lin, J.Y., Feng, Y.P., Ding, J., van, L.H., Yin, J.H. Room-Temperature Ferromagnetism in Carbon-doped $\mathrm{ZnO}$ Physical Review Letters 99 (12) 2007: pp. 127201. https://doi.org/10.1103/PhysRevLett.99.127201

18. Wang, T., Liu, Y., Fang, Q., Wu, M., Sun, X., Lu, F. Low Temperature Synthesis Wide Optical Band Gap Al and (Al, $\mathrm{Na}$ ) Co-doped $\mathrm{ZnO}$ Thin Films Applied Surface Science 257 (6) 2011: pp. $2341-2345$. https://doi.org/10.1016/j.apsusc.2010.09.100

19. Lee, W., Shin, S., Jung, D.R., Kim, J., Nahm, C., Moon, T., Park, B. Investigation of Electronic and Optical Properties in $\mathrm{Al}-\mathrm{Ga}$ Codoped $\mathrm{ZnO}$ Thin Films Current Applied Physics 12 (3) 2012: pp. 628-631. https://doi.org/10.1016/j.cap.2011.09.008

20. Pei, G., Xia, C., Wu, B., Wang, T., Zhang, L., Dong, Y., $\mathbf{X u}, \mathbf{J}$. Studies of Magnetic Interactions in Ni-doped $\mathrm{ZnO}$ from First-principles Calculations Computational Materials Science 43 (3) 2008: pp. 489-494. https://doi.org/10.1016/j.commatsci.2007.12.012

21. Liu, S.H., Huang, J.C.A., Lin, C.R., Qi, X. Electrical Transport and ac Conductivity Properties of Hydrogenated Annealing V-doped $\mathrm{ZnO}$ Journal of Applied Physics 105 (7) 2009: pp. 07C502. https://doi.org/10.1063/1.3055274

22. Shao, J.Z., Dong, W.W., Li, D., Tao, R.H., Deng, Z.H., Wang, T., Meng, G., Zhou, S., Fang, X.D. Metalsemiconductor Transition in Nb-doped $\mathrm{ZnO}$ Thin Films Prepared by Pulsed Laser Deposition Thin Solid Films 518 (18) 2010: pp. 5288-5291. https://doi.org/10.1016/j.tsf.2010.04.068

23. Lin, J.M., Zhang, Y.Z., Ye, Z.Z., Gu, X.Q., Pan, X.H., Yang, Y.F., Lu, J.G., He, H.P., Zhao, B.H. Nb-doped ZnO Transparent Conducting Films Fabricated by Pulsed Laser Deposition Applied Surface Science 255 (13) 2009: pp. 6460-6463. https://doi.org/10.1016/j.apsusc.2009.01.002

24. Gokulakrishnan, V., Parthiban, S., Jeganathan, K. Ramamurthi, K. Structural, Optical, and Electrical Properties of Nb-Doped ZnO Thin Films Prepared by Spray Pyrolysis Method Journal of Electronic Materials 40 (12) 2011: pp. 2382. https://doi.org/10.1007/s11664-011-1755-1

25. Xu, J.W., Wang, H., Jiang, M.H., Liu, X.Y. Properties of Nb-doped ZnO Transparent Conductive Thin Films Deposited by Rf Magnetron Sputtering Using a High Quality Ceramic Target Bulletin of Materials Science 33 (2) 2010: pp. 119-122. 
https://doi.org/10.1007/s12034-010-0016-X

26. Wang, L., Meng, L., Teixeira, V., Song, S., Xu, Z., Xu, X. Structure and Optical Properties of ZnO: V Thin Films with Different Doping Concentrations Thin Solid Films 517 (13) 2009: pp. 3721-3725. https://doi.org/10.1016/j.tsf.2008.12.043

27. Krithiga, R., Chandrasekaran, G. Synthesis, Strucutral and Optical Properties of Vanadium Doped Zinc Oxide Nanograins Journal of Crystal Growth 311 (21) 2009: pp. 4610-4614. https://doi.org/10.1016/j.jcrysgro.2009.08.033

28. Perdew, J.P., Chevary, J.A., Vosko, S.H., Jackson, K.A., Pederson, M.R., Singh, D.J., Fiolhais, C. Atoms, Molecules, Solids, and Surfaces: Applications of the Generalized Gradient Approximation for Exchange and Correlation Physical Review B 46 (11) 1992: pp. 6671. https://doi.org/10.1103/PhysRevB.46.6671

29. Segall, M.-D., Lindan, P.-J., Probert, M.-A., Pickard, C.J., Hasnip, P.-J., Clark, S.-J., Payne, M.-C. Firstprinciples Simulation: Ideas, Illustrations and the CASTEP Code Journal of Physics: Condensed Matter 14 (11) 2002: pp. 2717.

https://doi.org/10.1088/0953-8984/14/11/301

30. Abbassi, A., El Amrani, A., $\quad$ Ez-Zahraouy, H., Benyoussef, A., El Amraoui, Y. First-principles Study on the Electronic and Optical Properties of Si and Al Co-doped Zinc Oxide for Solar Cell Devices Applied Physics A 122 (6) 2016: pp. 584. https://doi.org/10.1007/s00339-016-0111-y

31. Monkhorst, H.J., Pack, J.D. Special Points for BrillouinZone Integrations Physical Review B 13 (12) 1976: pp. 5188. https://doi.org/10.1103/physrevb.13.5188

32. Mahmood, A., Tezcan, F., Kardaş, G., Karadă̆, F. Effect of Sr Doping on the Electronic Band Structure and Optical Properties of ZnO: A First Principle Calculation Journal of Applied Physics 122 (11) 2017: pp. 113102. https://doi.org/10.1063/1.5002075

33. Li, Y., Zhao, X., Fan, W. Structural, Electronic, and Optical Properties of Ag-doped $\mathrm{ZnO}$ Nanowires: First
Principles Study The Journal of Physical Chemistry C 115 (9) 2011: pp. 3552-3557.

https://doi.org/10.1021/jp1098816

34. Shaw, A., Wrench, J.S., Jin, J.D., Whittles, T.J., Mitrovic, I.Z., Raja, M., Dhanak, V.R., Chalker, P.R., Hall, S. Atomic Layer Deposition of Nb-doped $\mathrm{ZnO}$ for Thin Film Transistors Applied Physics Letters 109 (22) 2016: pp. 222103. https://doi.org/10.1063/1.4968194

35. Wu, Y., Li, C., Li, M., Li, H., Xu, S., Wu, X., Yang, B. Microstructural and Optical Properties of Ta-doped ZnO Films Prepared by Radio Frequency Magnetron Sputtering Ceramics International 42 (9) 2016: pp. 10847-10853. https://doi.org/10.1016/j.ceramint.2016.03.214

36. Si, X., Liu, Y., Wu, X., Lei, W., Xu, J., Du, W., Zhou, T., Lin, J. The Interaction between Oxygen Vacancies and Doping Atoms in $\mathrm{ZnO}$ Materials \& Design 87 2015: pp. 969-973. https://doi.org/10.1016/j.matdes.2015.08.027

37. Bechstedt, F., Tenelsen, K., Adolph, B., Del Sole, R. Compensation of Dynamical Quasiparticle and Vertex Corrections in Optical Spectra Physical Review Letters 78 (8) 1997: pp. 1528. https://doi.org/10.1103/PhysRevLett.78.1528

38. Si, X., Liu, Y., Wu, X., Lei, W., Lin, J., Gao, T., Zheng, L. Al-Mg Co-doping Effect on Optical and Magnetic Properties of $\mathrm{ZnO}$ Nanopowders Physics Letters A $379(22-23)$ 2015: pp. 1445-1448. https://doi.org/10.1016/j.physleta.2015.03.025

39. Lu, X., Liu, Y., Si, X., Shen, Y., Yu, W., Wang, W., Luo, X., Zhou, T. Temperature-Dependence on the Structural, Optical, And Magnetic Properties of Al-Doped ZnO Nanoparticles Optical Materials 62 2016: pp. 335-340. https://doi.org/10.1016/j.optmat.2016.09.037

40. Jin, Z., Qiao, L., Guo, C., He, Z., Liu, L., Rong, M. Firstpriniciple Study of Electrical and Optical Properties of (Al, $\mathrm{Sn})$ Co-doped $\mathrm{ZnO}$ Optik-International Journal for Light and Electron Optics 127 (4) 2016: pp. 1988-1992. https://doi.org/10.1016/j.ijleo.2015.10.224 